\title{
The Evolution and Reconstruction of the Policy of Sino-Foreign Cooperative Education in the Sight of Internationalization of Higher Education
}

\author{
Dan Wang \\ International Education Center, Shanghai Publishing and Printing College, Shanghai, China \\ Email: $563169421 @ q q . c o m$
}

How to cite this paper: Wang, D. (2019) The Evolution and Reconstruction of the Policy of Sino-Foreign Cooperative Education in the Sight of Internationalization of Higher Education. Open Journal of Social Sciences, 7, 234-245.

https://doi.org/10.4236/jss.2019.711016

Received: November 11, 2019

Accepted: November 19, 2019

Published: November 22, 2019

Copyright () 2019 by author(s) and Scientific Research Publishing Inc. This work is licensed under the Creative Commons Attribution International License (CC BY 4.0).

http://creativecommons.org/licenses/by/4.0/ (c) (i) Open Access

\begin{abstract}
Globalization has been the development trend of the world economy since the 1980s. The globalization of higher education is especially affected by economic globalization, in this context, Sino-Foreign cooperative education in higher education emerging. The development, after more than 30 years of exploration and practice, of Chinese foreign cooperation in running schools is in high speed, and the scale, level and mode of running schools have tremendously changed, which is bound up with the incentive policies of our government. Based on the evolution and review of China's Sino-Foreign cooperative education policy, this paper will analyze the problems and shortcomings of the policy, heading first. It is the policy suggestions that we need make out, of Sino-Foreign cooperative education suitable for China's national conditions from the perspective of higher education nationalization, which is expected to be beneficial to the promotion of China's higher education internationalization process and the optimization of Sino-Foreign cooperative education.
\end{abstract}

\section{Keywords}

Higher Education, Internationalization, Sino-Foreign Cooperative Education, Policies, Suggestions

\section{Background}

The internationalization of higher education has been an inevitable trend in the process of economic globalization. Many countries have issued policies to promote higher education cooperation, to make mutual promotion and mutual im- 
provement, and to burst out the development and prosperity of higher education internationalization. One of the three carriages of higher education in China, Sino-Foreign cooperative education, has emerged. With the vigorous development of Sino-Foreign cooperative education, different policies and regulations in different periods have issued by China's education departments. In the perfecting process of the policy system, a series of achievements have been made, which are the escort to promote the internationalization of higher education in China. This paper traces back to the source, reviews and analyzes the evolution process of Chinese foreign cooperative education policy in the past 40 years. At the same time of affirming the effect, dialectically analyzing the shortcomings of the policy, and, actively exploring the countermeasures and suggestions, based on the practical level, of Sino-Foreign cooperative education in the process of promoting the internationalization of higher education. It can pave the way for the internationalization of higher education and reconstruct the practical value of the policy system.

\section{The Evolution and Achievements of Sino-Foreign Cooperative Education Policy}

The policy system of Sino-Foreign cooperative education is an organic integrity composed of a series of decrees, rules, regulations and measures formulated and issued by the Chinese government and the education department in order to support and mediate the policy. In the nearly 40 years of exploration, it has experienced five stages: policy absence, policy germination, policy issuance, policy legalization and policy implementation, as follows:

\subsection{Seeking-The Evolution of the Policy of Sino-Foreign Cooperative Education since the Reform and Opening Up}

After the Reform and Opening up in the 1980s, Sino-Foreign cooperative education has experienced five stages: Policy absence, policy germination, policy promulgation, policy legalization and policy implementation.

Firstly, policy absence (1978-1993). In 1978, the policy of Reform and Opening up has been decided in the Third Plenary Session of the Eleventh Central Committee of the Communist Party of China, laying the foundation for the germination of Sino-Foreign cooperative education. Then, Deng Xiaoping pointed out that China's education should keep pace with modernization, the world and the future, providing ideological guidance for Sino-Foreign cooperative education. In 1985, the Central Committee of the Communist Party of China issued the Decision of the Central Committee of the Communist Party of China on the reform of the education system, which clearly pointed out that we should actively open up, striving to create conditions, ensuring that China's education is in line with the achievements of world civilization, and providing policy basis for Sino-Foreign cooperative education. These ideas and policies quietly clear the obstacles for Sino-Foreign cooperative education, reflecting the 
vision and firm determination of the Chinese government in the development of education.

Secondly, policy germination (1993-1994). The opening up of right of education will last endless. The first step is to donate money to help students from Hong Kong, Macao and Taiwan, overseas Chinese and foreign friends. Despite the undefined proposal to allow Sino-Foreign cooperative education, it provides enough space for the development and exchange of Sino-Foreign cooperative education. With the inclining demand for Sino-Foreign cooperative education, policy absence has seriously hindered the further opening up of the right of education and the development process of educational modernization in China. Under the pressure of the situation, the former State Education Commission urgently formulated and publicly released the Notice on Cooperative Education by Overseas Institutions and Individuals in China, selected and solved the most urgent problems which faced in the process of Sino-Foreign cooperative education. Also, the connotation, scope, type, main body and relevant management methods of Sino-Foreign cooperative education are clarified. The promulgation of the circular makes up shortcomings of policy absence of Sino-Foreign cooperative education, and frames preliminarily for the formulation and improvement of the policy of Sino-Foreign cooperative education in the future.

Thirdly, policy promulgation (1995-2003). Comparatively speaking, the first policy of Sino-Foreign cooperative education implemented publicly is the Interim Provisions on Sino-Foreign Cooperative Education issued by the former State Education Commission in 1995. The paper clearly defines and elaborates the concept, principle, approval process, main body and leadership system, certificate and diploma issuance of Sino-Foreign cooperative education, which opens a new chapter of policy guidance of Sino-Foreign cooperative education. Subsequently, a series of policies and regulations have been issued, such as the Education Law of the People's Republic of China, the Vocational Education Law, the Higher Education Law, and the Notice on Strengthening the Management of Degree Granting in Sino-Foreign Cooperative Education. Rendering clear guidance and norms to the management and supervision in the process of Sino-Foreign cooperative education is like a timely rain, which moistens the vast soil of Sino-Foreign cooperative education.

Fourthly, policy legalization (2003-2010). Relevant laws has not been issued at the beginning of the development of Sino-Foreign cooperative education, but takes policies as the basic guidance, which makes the legal color of the policy system of Sino foreign cooperation in running schools weak. It was not until the year of 2003 that the State Council formulated and issued the Regulations of the People's Republic of China on Sino-Foreign Cooperative Education, which became the first collection of regulations and policies on Chinese foreign cooperation with legal features. The promulgation of the Regulations marks that $\mathrm{Si}$ no-Foreign cooperative education has gradually stepped into the track of legalization. It is obvious that the introduction of high-quality education resources is the fundamental task of implementing Sino-Foreign cooperative education, and 
higher education and vocational education are the focus of Sino-Foreign cooperative education. Subsequently, The Measures for the Implementation of the Regulations of the People's Republic of Sino-Foreign Cooperative Education supplemented and refined the Regulations, which is a policy specially aimed at the new problems and new situations in the process of Sino-Foreign cooperative education, and strengthened the supervision and management of education. Above two regulations jointly turn into the policy subject and legal support of Sino-Foreign cooperative education.

Fifthly, policy implementation (2010 to present). After the establishment of the policy system of Sino-Foreign cooperative education, the Outline of National Long-Term Education Reform and Development Plan (2010-2020) has been issued, which has a far-reaching impact on China's education in 2010. It not only bases on the top-level design as the first ten-year plan of China's education, but also puts forward clear educational development goals and reform programs. In addition, we will further refine the development objectives of Sino-Foreign cooperative education, focusing on attracting high-quality educational resources, striving for cooperation with international famous schools, educational research institutions and enterprises, jointly creating and implementing research projects, and achieving the purpose of exchange, learning and independent innovation in cooperation. Meanwhile, we should emphasize the introduction of high-quality talents, and encourage and support excellent overseas students, overseas Chinese, overseas teachers, experts and scholars to come to China to engage in education and research development. The government of Liaoning province, Tianjin, Henan province, Jiangsu provinces and other provinces and cities have set up pilot projects of Sino foreign cooperation in running schools under the guidance of the Outline, positively tried and continuously innovated, and accumulated a lot of high-quality and high-standard experience in Sino-Foreign cooperative education. In 2016, the State Council issued Several Opinions on the Opening up of Education in the New Era, which improved and innovated the top-level design, system improvement, process supervision and theoretical support of Sino-Foreign cooperative education in combination with varying situations. In view of the key and difficult problems in the process of Sino-Foreign cooperative education, this paper demonstrates clear reform opinions, and strives to promote the root of the reform plan of Sino-Foreign cooperative education on the basis of expanding its scale, to realize the improvement of quality and efficiency.

\subsection{Achievements-The Effect of the Policy of Sino-Foreign Cooperative Education since the Reform and Opening Up}

The history of higher education in China, integrally, the strategy adopted in its internationalization process can be summarized as strategy-introversive type-to achieve internalization and absorption by means of learning foreign advanced models and experiences and introducing high-quality education resources, to make it internally drive to develop education [1]. After nearly 4 decades of ex- 
ploration and practice, the policy of Sino-Foreign cooperative education has changed from scratch, from theory to practice, from single policy to system formation. It has accumulated a lot of experience in Sino-Foreign cooperative education, not only that, but also steadily promoted the internationalization and high-end of China's higher education. On the one hand, the improvement of Sino-Foreign cooperative education policy has promoted the continuous development of overseas education policy, Chinese as a foreign language policy and study-abroad policy, paving a way for China's talents and culture to go out. On the other hand, the policy of Sino-Foreign cooperative education has excited various international higher education institutes, making scale of institutes and educational projects increasing with each passing day. Confucius Institutes, spreading all over the world, upsurge Chinese-learning and make cultural output be accelerated and the reshaped cultural confidence. At the same time, the evolution and development of Sino-Foreign cooperative education also provides many opportunities for the introduction of high-quality education talents and resources. While we are constantly introducing foreign education courses, teaching concepts and teaching models to activate the vitality of China's higher education development, in turn, we are promoting China's higher education to be in line with the internationalization, and realizing the dream of building more world-class universities into a powerful country in education by means of continuous introduction, absorption and learning.

\section{Problems in China's Policy of Sino-Foreign Cooperative Education}

\subsection{Lack of Policies Timeliness on Sino-Foreign Cooperative Education}

It is not difficult to find that, looking back on the evolution of Sino-Foreign cooperative education, the realization of Sino-Foreign cooperative education is largely based on the actual needs. Compared with the actual needs of the development of higher education in China and the pace of internationalization, the introduction of the policy of Sino-Foreign cooperative education is obviously lagging behind, which is mainly manifested in two aspects: firstly, the lag of the time of policy introduction. In the 1980s, there were inclining cooperatively run schools in China. However, absence of clear guiding policies brings about problems frequently, such as unclear approval authority, incomplete approval process and so on. What's worse, some overseas criminals are provided for a criminal opportunity, resulting in endless cases of educational fraud. Fortunately, the first policy of Sino-Foreign cooperative education came late in 1993. In this year, the regulations and policies differrelatively from the actual needs of Sino-Foreign cooperative education, and the policy revision takes a long time. For example, in 2008, some experts and scholars clearly pointed out that there are problems in the current Sino-Foreign cooperative education. Nevertheless, it was not until 2013 that the relevant units adopted the opinions for minor revision, and most of the problems in reality are still pendent. Therefore, the lag of Sino-Foreign 
cooperative education in the process of promulgation and revision has seriously hindered the internationalization of higher education in China. Secondly, the policy content lags behind. There are some problems in the policies of Sino-Foreign cooperative education, which are not in line with the reality and seriously lag behind the reality, compared with the actual needs of Sino-Foreign cooperative education. For example, Sino-Foreign cooperative education, in a comprehensive sense, there should be two modes included: overseas education and domestic education. However, around the 1990s, Chinese universities went abroad to seek opportunities for cooperation in overseas education, accordingly, overseas cooperative education was excited. In 1995, the Interim Provisions on Sino-Foreign Cooperative Education has been issued, which defined the policy as cooperative activities in the implementation of education and teaching in China [2]. This content in the Provisions clearly separates the two closely related modes of "Introduction" and "going out", and excludes "going out" from the legally agreed mode of Sino-Foreign cooperative education. This one-sided policy will inevitably lead to wrong orientation and lay unknown hidden dangers for the overall development of Sino-Foreign cooperative education.

\subsection{Unreasonable Policies Statement on Sino-Foreign Cooperative Education}

It is claimed accurate words and clear expressions for any policy to work better. However, there are many ambiguous meanings, unclear definitions and unscientific expressions throughout the policy of Sino-Foreign cooperative education. For example, the definition of "quality education resources" is vague. As mentioned above, the starting point of Sino foreign cooperative education policy is to attract more foreign high-quality talents and educational resources. However, the "quality education resources" has been given without a clear definition. It is only vaguely equivalent to such contents as "famous foreign educational institutions", "generally recognized academic level and quality of education and teaching", "introduction of domestic urgently needed courses and textbooks with advanced international standards". It is precisely because of the vagueness and unclear definition of China's policies that the quality of Sino foreign cooperative education is low and criticized. Therefore, it should be the focused problem to be solved to clarify "what is high-quality education resources". At the same time, there are some descriptive problems in the existing policy articles, such as contradiction between the beginning and the end, repeated discussion, which greatly affect the effectiveness of the policy.

\subsection{Inadequate Implementation of the Policy on Sino-Foreign Cooperative Education}

The policy belongs to the theoretical achievement. If it works in the real society, the implementation is the key. The policy of Sino-Foreign cooperative education has experienced 40 years of development. Although it tends to be improved gradually and its vitality is increasing gradually, there are two major problems, 
one of the two is the lag of implementation and the other is the distortion of implementation, which seriously limits the value reconstruction of Sino-Foreign cooperation in the practice. For example, the State Council issued the Regulations of the People's Republic of China on Sino-Foreign Cooperative Education in 2003, which clearly stated that the people's governments, education departments and other administrative departments of all provinces, autonomous regions and municipalities directly under the central government all enjoy the supervision power over local Sino-Foreign cooperative education according to law. It is also necessary to entrust professional organizations to regularly evaluate the education and teaching of Sino-Foreign cooperative education and publish the evaluation structure for the whole society [3]. However, it was not until 2009 that the education department chose four provinces and regions such as Tianjin as the pilot for evaluation, and the first round of pilot evaluation was completed in 2012. It can be seen that the policy of Sino-Foreign cooperative education has not been implemented in time since its promulgation, which will greatly prolong the process of internationalization of higher education in China.

\section{Realistic Reconstruction of the Policy of Sino-Foreign Cooperative Education in the Perspective of Internationalization of Higher Education}

In February 2016, the Several Opinions on the Opening up of Education in the New Era was issued general office of the Central Committee of the Communist Party of China and the State Council, flagging a new stage that Sino-Foreign cooperative education has entered, and defining the development goal of Sino-Foreign cooperative education in this stage, "improving quality and efficiency, serving the overall situation and enhancing capacity". However, the policy system of Sino-Foreign cooperative education is an organic combination of relevant laws, regulations, policies and implementation measures. Therefore, we will also actively explore the practical reconstruction approaches and effective strategies of Sino-Foreign cooperative education in the perspective of internationalization of higher education from the four aspects of policy itself, external factors, policy value and implementation and development. It has important practical significance under the background of internationalization of higher education.

\subsection{Keep Pace with the Times and Improve the Policy of Sino Foreign Cooperation in Running Schools}

After nearly 4 decades of exploration and development, initially, the policy system of Sino-Foreign cooperative education has been established in China, but there are still some historic problems, such as the lack of timeliness, controversial content expression, incomplete content, etc. Some new problems have gradually emerged with the further development of Sino-Foreign cooperative education, further increasing the gap between the existing policy system and the actual situation of the country, seriously affecting the effectiveness. Based on this, we need to keep pace with the times, correct and cure the historic problems and 
new present problems in the policy of Sino-Foreign cooperative education, and constantly improve the policy of Sino-Foreign cooperative education. Specifically, we can start from the following aspects: firstly, actively introduce "going out" and frame a reasonable policy. According to the Opinions issued in 2016, the education goal of the new era should be based on two basic points at home and abroad, and overall situation. Domestic cooperative education and overseas cooperative education are the capable assistants of Sino-Foreign cooperative education, which should go hand in hand and develop commonly. Therefore, we should learn from foreign successful experience and advanced models by "going out". With the help of "Introduction", we will integrate the theoretical achievements we have learned into the latest policy of Sino-Foreign cooperative education. Promote the dynamic update and continuous improvement of relevant regulations, opinions and methods to meet the international development needs of China's higher education in an all-round way. Secondly, establish and improve of the policy system for Sino-Foreign cooperative education. After improving its content and framework, it is also necessary to establish laws and regulations supporting the policies one by one, to advance the legalization process of Sino-Foreign cooperative education in an orderly manner. At the same time, we will further sort out the improved policies and regulations, integrate, clarify and clean up the repeated and contradictory policies, and ensure the accuracy of the existing policy content and framework [4]. At the same time, we should make a good connection between the central government and the local government, encourage the local government to formulate supporting policies for $\mathrm{Si}$ no-Foreign cooperative education in accordance with the unified deployment of the central government and the actual situation of the local government, further expand and improve the policies for Sino-Foreign cooperative education, enhance the pertinence and scientificity, and jointly drive the international development of higher education in China.

\subsection{Skillfully Borrow External Strength to Drive National Education Development Strategy}

With the development of the times, more opportunities and challenges of the development of Sino-Foreign cooperative education is emerging. How to use the opportunity and platform of Sino-Foreign cooperative education to drive the development in depth is worth thinking and exploration. Combined with the current actual situation, we can further expand the effectiveness of Sino-Foreign cooperative education from two aspects as follows. Firstly, we will promote the implementation of the strategy of "One Belt and One Road", relying on Sino-Foreign cooperative education. With the link of "One Belt and One Road", Sino-Foreign cooperative education can penetrate into the western regions such as Xinjiang, Ningxia and Gansu, and promote the balanced development of higher education resources in China. The main body of cooperation in running schools can also strengthen the project development and research cooperation in the fields of mariculture, pelagic fishery, marine biopharmaceutical and mari- 
time tourism in the light of the actual situation of all countries along the Belt and Road, and make full use of the advantageous resources of all the countries along the border to transform them into the motive force for the development of international education, overcome the difficulties of science and technology and enhance the effectiveness of Sino-Foreign cooperative education. At the same time, the comprehensive implementation of the "One Belt and One Road" strategy has provided a platform for the exchange of talents among all countries, adding the team of overseas students growing, and young talents from all over the world carry out in-depth exchanges and cooperation in many fields such as education, employment, entrepreneurship, skills and so on, and jointly construct the common destiny of human destiny. Secondly, what we will promote the implementation of the strategy of invigorating the country through science and education and strengthening the country through human resources depends on Sino-foreign cooperative education. On the one hand, relying on the policy, we should actively introduce foreign high-quality educational resources through multiple channels and at multiple levels, accelerate the integration of high-quality resources with higher education, promote the reform of higher education, train more high-level international talents for our country, and realize the "double first-class" construction goal of China's universities better and faster. On the other hand, we should, based on Sino-Foreign cooperative education, actively seek in-depth cooperation with foreign universities, enterprises and scientific research institutions, cultivate more high-tech talents for China's modernization, promote innovative development of science and technology, and fully implement the strategy of rejuvenating the country through science and education. At the same time, we should also adhere to the "Inclusive" attitude, strive to attract and encourage foreign high-end technical talents, educational institutions and academic teams to enter China, establish and improve the existing international research and education cooperation platform, encourage overseas students and overseas Chinese to return to China for entrepreneurship, strengthen the strategy of Reinvigorating China through Human Resource Development to work better [5].

\subsection{Value Sublimation and Construction of International Education Development System}

The fundamental purpose of improving the policy system of Sino-Foreign cooperative education is to drive the international development of education, to pool resources and dredge channels for the construction of world-class universities. Therefore, we should closely link the improvement of the policy system of Sino-Foreign cooperative education with the improvement process of the international education development system, promote each other and deepen the practical value of the system. Firstly, strengthen the top-level design, which mainly refers to the unified planning of all aspects and elements related to the overall situation based on the overall situation, on the basis of the integration of re- 
sources, conducting task allocation and goal setting. Throughout the internationalization system of higher education in China, there are many problems such as incomplete supporting policies and lax implementation of policies and regulations. The reason lies in the lack of scientific and perfect top-level design for the international development of higher education in China. At present, China's opening up of educational authority is more powerful, of which is a more close connection between national governance and social construction. Therefore, we must base ourselves on the overall work of the party and state building, and integrate the existing resources of education, culture, science, trade and tourism from the strategic needs of "One Belt and One Road", "the strategy of rejuvenating the country through science and education" and "the strategy of reinvigorating China through human resource development". We should make a scientific strategic plan and top-level design to support the nationalization of higher education and avoid blindness in the implementation of the plan. Secondly, we need to improve the system. According to the requirements of the Opinions, Sino-Foreign cooperative education should "improve the access system, reform the examination and approval system, carry out evaluation and certification, and strengthen the exit mechanism" [6]. Therefore, in view of some unreasonable terms in the existing regulations implementation measures, we should revise them practically, start the revision process, clarify the specific time limit for the completion of the revision, and improve the completion efficiency of the revision process. At the same time, the Law on the Promotion of Internationalization of Higher Education or the Law on International Education should be formulated to promote the integration of various forces in the form of laws. We should deal with the problems and disputes in the process of internationalization of higher education, and promote the harmonious and steady progress of the process of internationalization of higher education.

\subsection{Pay Close Attention to the Implementation and Promote the Steady Improvement of International Education}

Firstly, clarify the rights and responsibilities, and build an efficient organization and operation mechanism. The key is to make clear the relationship, to carry out the policy of internationalization of higher education, among the three main bodies: the state, the districts and the universities. Focusing on the basic positioning of university running, the power responsibility relationship between the state and the local government and the supervision function of social forces, the governance system of "State-Districts-Universities-Third Party organization" is actively constructed. Set up a special higher education internationalization guidance agency under the State Council, which is responsible for the top-level design, overall planning and overall deployment of higher education internationalization; set up a higher education internationalization guidance agency within the local scope under the local government, which is responsible for the implementation and implementation of relevant laws and policies. We should design a 
special international affairs management organization in colleges and universities, encourage social forces to establish a third-party organization, and undertake the supervision, evaluation, certification, consultation and other work of the internationalization of higher education. Secondly, supervise and feedback, establish and improve the quality assurance system. On the one hand, we should increase the amount of channels and introduce diversified supervision forces. About whether it is universities, society, government, teachers and students, parents, third-party institutions, they are all the interest subjects of the internationalization of higher education, and they all enjoy the right to supervise the internationalization process of higher education according to law. Therefore, we should actively open up channels, fully mobilize the supervision power and enthusiasm of all stakeholders, establish a perfect supervision and reporting system and information disclosure system, and promote the openness and transparency of the internationalization process of higher education. On the other hand, rationalize the information feedback mechanism. How to ensure the effectiveness of supervision focuses on the timely and effective feedback of supervision information results. Therefore, we should establish a smooth feedback mechanism of supervision information on the basis of strengthening supervision authority. A special supervision information collection and processing mechanism, under the leadership of the government, shall be established to ensure that the information from all supervision subjects can be collected and fed back in time, and to guarantee the supervision right and the right to know of the public. In view of the problems found in the supervision process, the responsible subject shall be ordered to rectify in time, and appropriate punishment measures shall be selected according to the severity of the problems.

Internationalization has become a general rule for the development of higher education in various countries with the continuous progress of globalization, and the steady improvement of the quality of running a school. Since the reform and opening up, China has been committed to exploring the development strategy of higher education, constantly improving the policies and regulations of Sino foreign cooperation in running schools, and promoting China's higher education to be in line with the international standards. However, a journey of a thousand miles begins with a single step, and the road to perfection of the policy of Sino foreign cooperation in running schools is tortuous and long. Only can we stand on the present, look into the future, face up to the shortcomings, seek from the top and the bottom, and adhere to the combination of "Introduction" and "going out". Only in this way can we improve and activate the policy framework and legal system of Sino-Foreign cooperative education, so as to realize the value reconstruction and the connotative development of China's higher education in the process of promoting the internationalization of China's higher education.

\section{Conflicts of Interest}

The author declares no conflicts of interest regarding the publication of this paper. 


\section{References}

[1] Xue, W.Y. (2016) Sino-Foreign Cooperation in Higher Education in Quality Construction. Chinese Higher Education Research, No. 2, 12-19.

[2] Li, Y.B. and Xie, L.H. (2013) Sino-Foreign Cooperative Education Mode: Practical Reflection and Path Selection. Jiangxi Social Sciences, No. 10, 244-248.

[3] State Council (2003) Order of the State Council of the People's Republic of China (No. 372)-Regulations of the People's Republic of China on Chinese Foreign Cooperation in Running Schools. Bulletin of the State Council of the People's Republic of China, No. 12, 5-10.

[4] Zhuo, Y. (2014) How to Develop Chinese Foreign Cooperative Education in Local Areas. Nanfang Daily, No. 12, sc04.

[5] Li, J. (2017) The Development of Cross-Border Higher Education and the Construction of Quality Assurance System-Based on the Perspective of Sino-Foreign Cooperative Education. Journal of Jimei University, No. 5, 35-40.

[6] General Office of the CPC Central Committee and General Office of the State Council (2016) Several Opinions on the Opening Up of Education in the New Era Printed and Distributed. Office Business, No. 10, 4. 